\title{
Pesquisando masculinidades juvenis em um contexto escolar: desafios metodológicos
}

Neide Pinto dos Santos ${ }^{1}$ Mirela Figueiredo Iriart $^{2}$

\begin{abstract}
Resumo:
A pesquisa, que será aqui discutida, objetivou compreender os sentidos e significados que os jovens produzem sobre masculinidades, em um contexto escolar no interior do Nordeste. Privilegiou-se a pesquisa de natureza narrativo-dialógica, considerando a importância das interações intersubjetivas no campo da pesquisa. Lançou-se mão de dispositivos metodológicos, como: observação participante; rodas de conversas; entrevistas narrativas; grupos de discussão, que fizeram emergir novas formas de posicionamento entre os participantes e a pesquisadora nos contextos investigados. $O$ protagonismo dos jovens durante a pesquisa e a escuta sensível da pesquisadora durante a pesquisa produziram efeitos subjetivos importantes para ambos, trazendo à tona a demanda dos jovens de que a escola promovesse espaços de debate e de participação para serem ouvidos e reconhecidos nas suas diversidades. O aprofundamento teórico e a incursão no campo de pesquisa apontaram para uma diversidade de experiências juvenis em relação à vivência da masculinidade. Apesar dessa escuta, pode-se afirmar que a escola ainda está longe de possibilitar a livre expressão e performatividade da diversidade de gênero entre jovens.
\end{abstract}

\section{Palavras-chave:}

Pesquisa Qualitativa. Jovens. Gênero. Masculinidade.

\section{Researching youth masculinities in a school context: methodological challenges}

\begin{abstract}
The research, which will be discussed here, aimed to understand the senses and meanings that young people produce about masculinities in a school context in the Northeast. Narrative-dialogical research was privileged, considering the importance of intersubjective interactions in the research field. Methodological devices such as participant observation; conversation wheels; narrative interviews and discussion groups gave rise to new forms of positioning between the participants and the researcher in the investigated contexts. The performance of young people during the research and the sensitive listening
\end{abstract}

\footnotetext{
1 Mestra em Educação, Professora do Instituto Federal Baiano. E-mail: neidesantos86@gmail.com. ORCID iD: http://orcid.org/ 0000-0002-2609-0943.

2 Doutora em Saúde Coletiva, Professora do Departamento de Educação da Universidade Estadual de Feira de Santana (BA) (UEFS). E-mail: mifis36@gmail.com. ORCID iD: http://orcid.org/0000-0001-5673-6787.
} 
of the researcher produced important subjective effects for both. This effects brought to the fore the demand of young people for the school to promote spaces for debate and participation in order that they can be heard and recognized in their diversity. The theoretical deepening and incursion in the research field pointed to a diversity of youth experiences in relation to masculinity. Despite this listening, it can be said that the school is still far from enabling the free expression and performativity of gender diversity among young people.

Keywords: Qualitative Research. Young People. Genre. Masculinity.

\section{Investigar las masculinidades juveniles em um contexto escolar: desafios metodológicos}

Resumen: La investigación, que será discutida aquí, tuvo como objetivo comprenderlos sentidos y significados que los jóvenes producen sobre masculinidades, en un contexto escolar en el Nordeste. Privilegiamos la investigación de naturaleza narrativo-dialógica, considerando la importancia de las interacciones intersubjetivas en el campo de la pesquisa. Utilizamos los siguientes dispositivos metodológicos: observación participante; ruedas de conversación; entrevistas narrativas; grupos de discusión que hicieron emerger nuevas formas de posicionamiento entre los participantes y la investigadora en lo contexto investigado. El protagonismo de los jóvenes durante la investigación, en conjunto con la escucha sensible de la investigadora, produjeron importantes efectos subjetivos para ambos. Así como, puso en primer plano la demanda de los jóvenes para que la escuela promueva espacios de debate y de participación para que ellos sean escuchados y reconocidos en su diversidad. La profundización teórica e incursión en el campo de investigación apuntó a una diversidad de experiencias juveniles en relación con la vivencia de la masculinidad. A pesar de esta escucha, podemos decir que la escuela aún está lejos de permitir la libre expresión y performatividad de la diversidad de género entre los jóvenes.

Palabras clave: Investigación Cualitativa. Joven. Género. Masculinidad.

\section{Introdução}

Este artigo objetiva analisar concepções de masculinidades contra-hegemônicas por meio de uma pesquisa empírica com jovens em um contexto educacional público no interior do Nordeste, analisando os tensionamentos entre o discurso institucional e os discursos juvenis que perfuram os silenciamentos produzidos na escola.

A pesquisa com jovens em contexto educacional é o mote para construir-se uma reflexão sobre o percurso investigativo e os impactos que a pesquisa gera no contexto e nos participantes, sobretudo quando se está diante de objetos de investigação que encontram resistência no discurso escolar. Alguns aspectos metodológicos serão trazidos para o debate, buscando lançar luz sobre como a pesquisa de cunho dialógico opera efeitos sobre a dinâmica institucional.

Entende-se que a natureza da pesquisa com jovens, sobretudo em contextos educacionais, tem especificidades e nuances próprios que merecem ser refletidas e compartilhadas, possibilitando trazer à tona arranjos metodológicos mais dinâmicos e interativos.

As questões colocadas pela pesquisa, no âmbito do Mestrado em Educação, dizem respeito aos sentidos e significados que os jovens produziram sobre gênero e masculinidades, sobre os rituais e as provas, assim como sobre os diferentes arranjos identitários que se tramam nas relações dentro e fora da escola.

A partir desse recorte, aproximou-se o olhar sobre o cotidiano escolar, entendendo como as relações de gênero aí emergem, como resultado de formas de negociação que se dão entre escola, família, religião e sociedade. 
Inicia-se provocando uma discussão sobre a categoria da juventude e sua diversidade sociocultural, sobretudo quando demarcadas pelas relações de gênero. Em seguida, será debruçado sobre os modos de pesquisar na escola, desde as nuances da entrada em campo e o contexto discursivo até os efeitos produzidos com a pesquisa na relação entre pesquisadoras e participantes. E, por fim, serão analisados os discursos juvenis no seu potencial de resistência ao instituído e de negociação com as agências socializadoras.

\section{Sobre juventudes, masculinidades e educação}

Compreende-se as juventudes enquanto categoria social, levando em consideração as condições juvenis diversas, as diferentes configurações identitárias e as expressões culturais. Nesse estudo se faz pertinente pensar as relações de gênero de modo fluído e deslizante, bem como refletir sobre as interações entre masculinidades, culturas juvenis e contextos de socialização para poder-se compreender como modelos de masculinidades têm sido negociados entre os(as) jovens.

Um ponto importante de reflexão diz respeito ao exercício da desnaturalização das identidades de gênero, questionando a hegemonia das representações e as formas de subalternização daí derivadas, o que implica compreender-se como os processos de socialização familiar, escolar, religioso participam da construção das masculinidades.

Esse tema tem sido fomentado nos últimos anos por pesquisadores no âmbito acadêmico, $o$ que constitui avanços significativos na produção de novos conhecimentos nos estudos de gênero. No entanto, ainda são poucos os trabalhos que trazem a articulação entre masculinidades e juventudes no contexto educacional.

Os estudos de Connell e Messerschmidt (2013) nos ajudam a pensar o conceito de masculinidade hegemônica como um padrão de práticas que possibilita a dominação masculina, ao enfatizarem que a masculinidade hegemônica se difere de outras masculinidades, especialmente das chamadas masculinidades subordinadas. Os estudos de Machado e Seffner (2013) e de Joca (2016) nos ajudam a refletir sobre novas configurações de gênero e sexualidade e sobre produções de masculinidades experimentadas por jovens e que tensionam suas formas hegemônicas.

A construção das masculinidades acontece nas interações sociais e culturais, atravessadas pelos múltiplos processos de socialização familiar, escolar, midiática e religiosa. Dessa forma, é importante refletir-se sobre como as questões de gênero são significadas pelos(as) jovens no contexto escolar e o quanto essas significações são negociadas no processo de socialização, como rituais e provas sobre ser homem na nossa cultura, bem como sobre as experiências de preconceitos vivenciadas por alguns.

É importante considerar-se que as juventudes, na contemporaneidade, constituem-se a partir da tessitura de diferentes espaços formativos, para além de reproduzirem as exigências das instituições socializadoras tradicionais que tendem a reforçar padrões sociais. De acordo com Carrano (2009, p. 1-2):

Sem desconsiderar os pesos específicos das estruturas e condicionamentos sociais, um dos princípios organizadores dos processos produtores das identidades contemporâneas diz respeito ao fato dos sujeitos selecionarem as diferenças com as quais querem ser reconhecidos socialmente. Isso faz com que a identidade seja muito mais uma escolha do que uma imposição. Uma das mais importantes tarefas das instituições, hoje, seria a de contribuir para que os jovens pudessem realizar escolhas conscientes sobre suas trajetórias pessoais e constituir os seus próprios acervos de valores e conhecimentos que já não mais são impostos como heranças familiares ou institucionais. O peso da tradição encontra-se diluído e os caminhos a seguir são mais incertos. Os jovens fazem seus trânsitos para a vida adulta no contexto de sociedades produtoras de riscos - muitos deles experimentados de forma inédita, tal como o da ameaça ambiental e do tráfico de drogas -, mas também experimentam processos societários com maiores campos de possibilidades para a realização de apostas frente ao futuro. 
Quando os diferentes espaços de socialização dos(as) jovens são analisados do ponto de vista das relações de gênero, nota-se que as instituições família e religião se colocam tradicionalmente como referências significativas nesse processo de educação. No entanto, é pertinente refletir sobre como discursos sobre gênero, masculinidades e sexualidade têm sido enfrentados, praticados e experimentados por jovens no contexto escolar e sociopolítico atual.

Setton (2005, p. 342) sinaliza para a "emergência de uma nova ordem sociocultural, identificando a presença de uma maior circularidade de experiências e referências identitárias" na sociedade contemporânea. Isso nos impele a refletir sobre as diferentes vias de acesso à informação, bem como sobre a importância de entender "a heterogeneidade dos espaços em que se produz e se troca as informações, saberes e competência" (SETTON, 2005, p. 342). E, diante destas reflexões, é relevante discutir-se sobre os desafios, limites e possibilidades que a escola apresenta para dialogar com estes(as) jovens sobre suas experiências.

\section{Aspectos metodológicos: pesquisando masculinidades em contexto escolar}

A pesquisa com jovens em contexto escolar pretendeu ter uma postura de escuta e negociação com os diferentes atores, respeitando o cotidiano institucional, ao mesmo tempo em que buscou perfurar o instituído e fazer emergir as performances juvenis e as invisibilidades no contexto escolar.

A pesquisa de natureza narrativo-dialógica privilegia as interações intersubjetivas no campo da pesquisa, buscando produzir narrativas no encontro com os participantes, imergindo nos espaços, observando as performances e escutando os jovens (GERMANO; BESSA, 2010). A noção de implicação da pesquisadora no campo da pesquisa é importante ao considerar-se que os processos interativos provocados durante a pesquisa produzem reposicionamentos subjetivos entre os atores envolvidos.

A pesquisa aqui referida desenvolveu estratégias próprias para inserção no campo e construção de vínculos com os participantes, assim como dispositivos dialógicos para produção de dados, como: grupos de discussão, rodas de conversa e entrevistas narrativas. O contexto investigado apresentou suas especificidades em relação às rotinas escolares, à estrutura curricular. Apesar de a arquitetura angulosa das escolas guardar semelhanças com outras instituições de ensino, ao perscrutar-se seus corredores e se inserir na rede de significações ali produzida, novas nuances foram se apresentando e sendo decifradas ao longo da pesquisa. Reconheceu-se que a neutralidade é impossível e indesejável quando se pretende pesquisar com e sobre juventudes (MIRANDA et al., 2016).

Constituiu um desafio, aproximar-se dos(as) jovens, respeitando as dinâmicas próprias de suas vivências e experiências juvenis. A pesquisadora precisou estar disposta a escutar as suas vozes e os seus modos de pensar e se fez presente no cotidiano escolar. Fazer pesquisa com jovens foi um convite à pesquisadora a despir-se dos estereótipos do ser adulto e se permitir ser interpelada por eles(as), considerando que as juventudes constituem um momento singular da vida, com valor em si mesmo.

Sobre o desafio metodológico de pesquisar com jovens, Ferreira (2017, p. 17) afirma que:

Os mundos juvenis configuram, de fato, laboratórios que desafiam constantemente as ciências sociais, quer de um ponto de vista teórico, estimulando a criação de novos conceitos, quer de um ponto de vista metodológico, ativando a necessidade criar novos instrumentos (ou reequacionar métodos ortodoxos e técnicas de capacitação, sistematização e análise dessas mesmas realidades).

Diante desse desafio, os passos metodológicos precisam reinventar-se, considerando que "a cada novo desafio colocado pelo campo, um novo método precisa ser inventado" (FERREIRA, 2017, p. 18), assim como "juvenilizar" os métodos de pesquisa com os jovens, como destaca Ferreira (2017). Os 
desafios vão desde a inserção progressiva no campo e o olhar sobre o cotidiano escolar e suas nuances até a construção de dispositivos dialógicos que potencializem as construções discursivas. Para tanto, o uso de estratégias metodológicas diversas se fez importante, como: o uso dos diários de campo, os grupos de discussão, as rodas de conversa e as entrevistas narrativas, que foram suportes necessários para estreitar-se os laços afetivos no campo da pesquisa, fazendo emergir processos intersubjetivos.

Pesquisar com jovens no contexto escolar implicou pensar esse espaço como lugar de encontro com as diferenças e também como lugar potencial para a construção de novos saberes. Pesquisar gênero e sexualidade na escola, mais especificamente por uma mulher negra, jovem pesquisadora, fez-se deslocar posicionamentos e ressignificar as posições tradicionais binárias, gerando efeitos e afetos no percurso da pesquisa. Apesar de se propor falar de um tema presente no cotidiano da escola, bem como latente na sociedade contemporânea, foi preciso perguntar-se o porquê de as questões de gênero ainda serem vistas como "ameaça" a ponto de se impor uma cultura do silenciamento e do apagamento das diferenças no contexto escolar (LOURO, 2016). Isso trouxe o desafio de se pensar em estratégias metodológicas que promovessem a discussão de temáticas tão importantes, mas pouco problematizadas nesse contexto.

Considerando a importância da escola como local de pesquisa, o contexto desse estudo é uma escola pública situada em um bairro do centro no município de Feira de Santana (BA). Essa instituição foi criada em 1927 e atuou como Escola Normal de Feira de Santana. Em 1935 passou a ser denominada de Escola Normal Rural de Feira de Santana. Anos depois foi instituída como colégio do Estado e atualmente, após a inserção da educação profissional, ofertando cursos na área de Saúde, Gestão e Negócio, passou, em 2012, a ser considerada Centro de Educação em Saúde. Esta unidade de ensino trabalha hoje com as modalidades de Ensino Profissionalizante Integrado ao Ensino Médio e com a finalização do Ensino Fundamental e Médio, com 1900 estudantes aproximadamente.

A escolha da escola para realização da pesquisa levou em consideração o fato de a instituição estar situada no centro da cidade e receber estudantes de diferentes bairros, bem como a partir das conversas informais com uma professora da escola, que relatou situações vivenciadas pelos jovens, por exemplo, a dificuldade em saber lidar com práticas discriminatórias que envolviam jovens estudantes homossexuais. Possivelmente, um contexto em que as questões de gêneros estavam presentes, mas não se falava muito sobre o assunto. Também se considerou importante apostar na diversidade de sujeitos que se inserem nesse espaço escolar.

A inserção no campo teve duração de aproximadamente seis meses, tendo iniciado os primeiros contatos no mês de abril de 2018 e a última reunião com a coordenação no mês de outubro de 2018. Foram realizados encontros com a coordenação da escola, com professores(as) e com os(as) jovens para organizar o desenvolvimento das etapas da pesquisa, que envolveu aplicação de questionários, seis grupos de discussão e onze entrevistas narrativas.

As primeiras aproximações com a escola mobilizaram reflexões acerca do ato de pesquisar de forma colaborativa. Sobre a entrada no campo de pesquisa, os autores Ferreira e Raimundo (2017, p. 60) afirmam que "conquistar a confiança (pessoal e institucional) dos interlocutores e dos sujeitos empíricos nos investigadores e modelar as suas expectativas perante os objetivos da pesquisa é uma condição que deve ser estabelecida desde o momento da entrada no campo". Nessa escolha, o pesquisador(a) precisa de disposição para o diálogo. Escutar e falar torna-se um processo de interação dinâmica que envolve aprendizagens, deslocamentos compreensivos e propositivos sobre qual a melhor forma de pesquisar. Todo esse processo requereu sensibilidade para adentrar um cotidiano marcado por rotinas próprias que é, por vezes, imprevisível e que possui uma ordem estabelecida.

O diário de campo possibilitou registrar-se experiências de interação com o lócus de pesquisa. A escrita se teceu de forma livre e refletida, entrelaçando observações, sentimentos, aprendizagens e questionamentos sobre o vivido no cotidiano escolar no decorrer da investigação.

A intenção de nos aproximar-se dos(as) jovens de forma "amigável", como chama atenção Ferreira (2017), levou a iniciar os primeiros contatos através de dinâmicas de roda de conversa 
e com atividades lúdicas, a exemplo da proposta da caixa de opiniões e do jogo de perguntas e respostas. Essas estratégias possibilitaram aos jovens se sentirem mais à vontade para colocarem suas opiniões acerca do tema em estudo.

Os encontros com os(as) jovens foram interessantes do ponto de vista da liberdade juvenil de expressar-se sem formalidades. O acolhimento era desconfiado e ao mesmo tempo aberto à nova figura que deles se lhes apresentava. Nos agrupamentos constituídos por eles próprios no pátio, cantina e nas salas de aula, falou-se do estudo que se pretendia desenvolver na escola, convidando-os para um bate-papo inicial sobre o assunto. Como meio de iniciar a conversa, foi realizado um jogo de perguntas e respostas. A ideia era passar uma caixa, com perguntas previamente elaboradas, de mão em mão, cantarolando. Quando a música parasse, o jovem que estivesse com a caixa deveria retirar uma questão e colocá-la para o grupo responder.

Ao longo do tempo, os ditos e não ditos foram emergindo, fazendo surgir vozes silenciadas. O encontro dos jovens com a temática de gênero trouxe, para alguns, desconfortos e, para outros, a necessidade e curiosidade de falar mais sobre o assunto: "eu sou virgem, é sobre isso que quer falar?", pergunta uma jovem, quando a pesquisadora se aproximou com a caixa de opiniões. Outras falas dos jovens reforçavam a importância do tema: "é bom falar de gênero, porque ajuda as pessoas que têm a mente fechada a se abrir mais pra esse tema". Já outros, não queriam falar do assunto ou se posicionavam contrários à perspectiva de pensar gênero fora dos padrões construídos socialmente. As resistências apareciam também entre o corpo docente: "não falar sobre o assunto pode ser mais fácil" (relato de uma professora, no primeiro encontro com a pesquisadora), mas os transbordamentos vão se impondo e a minha presença fez emergir os nãos ditos: "aqui está cheio de viados e sapatonas" (relato da merendeira, quando a pesquisadora aguardava os estudantes no pátio da escola).

A resistência nos olhares, nas falas e expressões de alguns profissionais revelaram o quanto ainda as relações desiguais de gênero são naturalizadas. $O$ viés religioso foi pontuado por alguns como justificativa para não aceitação das masculinidades não hegemônicas na sociedade contemporânea. $\mathrm{O}$ respeito às diferentes identidades de gênero e sexuais era defendido pela maioria como necessário à boa convivência, no entanto, a diversidade de gênero e sexual não era aceita por todos(as), as identidades que se inscreviam fora do padrão heteronormativo eram vistas como desviantes e anormais.

Participaram da pesquisa jovens, homens e mulheres, estudantes do ensino médio, com faixa etária entre 15 a 23 anos. Consideramos que estes jovens homens e mulheres são atravessados pelas diferenças de gênero, raça/etnia, religião etc. Bem como trazem, para o cotidiano da escola, diferentes experiências e vivências de masculinidades.

Inicialmente, a pesquisa que pretendia estudar a constituição das masculinidades exclusivamente do ponto de vista de jovens homens, trouxe para a discussão as experiências das jovens mulheres que se consideravam masculinizadas. $\mathrm{O}$ aprofundamento teórico e a inserção no campo de pesquisa apontaram para uma diversidade de experiências juvenis em relação à vivência da masculinidade, tanto no que concerne às diferentes experiências entre os próprios homens (afeminado, homossexual, homem macho) quanto ao que perpassa às experiências de jovens mulheres nas suas diferentes identidades sexuais (bissexual, heterossexual e lésbica).

A aproximação com os jovens se deu de forma espontânea. Não houve uma apresentação formal. Após as rodas de conversa informais aplicou-se o questionário como estratégia para conhecer melhor os(as) jovens participantes da pesquisa. Buscou-se, nesta etapa, estreitar as relações com os(as) jovens, apresentando a proposta da pesquisa e os(as) convidando a participar das etapas posteriores.

Em meio à dinâmica da escola, com semanas de provas, organização por semestres e recesso entre um semestre e outro, iniciaram-se os grupos de discussão com os jovens homens e as jovens mulheres, 6 encontros com aproximadamente 12 participantes em cada encontro. No primeiro encontro foi realizada uma dinâmica de apresentação dos(as) participantes na constituição do grupo, bem como se tratou dos combinados. Na sequência, aconteceram 4 encontros temáticos 
trazendo as seguintes discussões: a relação do homem com o próprio corpo; relação do homem com a mulher; masculinidades na escola e as relações afetivas e sexuais entre homens e entre mulheres. Foi realizado um último encontro de encerramento e avaliação dos encontros.

A última etapa realizada foram as entrevistas, que objetivou a aproximação com as diferentes trajetórias juvenis relacionadas à vivência de suas masculinidades. Para composição das entrevistas, foram selecionados 8 jovens homens e 3 jovens mulheres, de acordo com as classificações de masculinidades sinalizadas pelos(as) jovens nos grupos de discussão: homem afeminado; homem macho alfa; homem homossexual; e, mulher masculina. As entrevistas tiveram duração entre $20 \mathrm{e}$ 40 minutos. Esta etapa da pesquisa se constituiu em um momento de escuta dos jovens e de suas trajetórias. As entrevistas realizadas com os jovens e as jovens que já vinham participando dos grupos de discussão foram facilitadas e fluíram com mais desenvoltura. Já os jovens com o perfil de macho alfa, que não participaram dos encontros em grupo, apresentaram maior resistência em se colocarem e falarem sobre suas vivências masculinas, demonstrando resistência desde o primeiro contato para participação nos grupos de discussão. No entanto, se colocaram à disposição para participar da etapa das entrevistas.

Os encontros iniciais com os(as) estudantes foram realizados nas salas de aula, corredores, cantina e pátio. E por fim, os grupos de discussão, na biblioteca. A abordagem com os jovens foi feita de forma a convidá-los para participarem, junto com a pesquisadora, dos debates sobre gênero e masculinidades. Sendo que a interação por meio de redes sociais, com a finalidade de articular os encontros, foi uma estratégia que possibilitou uma aproximação amistosa e favoreceu o diálogo e a horizontalidade.

Após a pesquisadora apresentar-se, ficou combinado que seria deixada na escola, em local de fácil acesso, uma caixa de opiniões para que eles pudessem escrever o que pensavam sobre gênero e sobre masculinidades, sem a necessidade de se identificarem. Na caixa, pela pesquisadora, confeccionada havia duas questões: (a) o que você pensa sobre gênero? e (b) o que você pensa sobre masculinidades e feminilidades?

Em seguida a essa etapa, que se denominou de "quebra de gelo", aconteceram as rodas de conversa para apresentar a proposta e marcar o início dos grupos de discussão com aqueles que respondessem aos questionários e desejassem continuar na pesquisa. A estratégia do grupo de discussão possibilitou a troca de vivências, o pensar e repensar das construções históricas e sociais das relações de gênero e o problematizar da naturalização dessas relações, que, em muitos casos, gera violência. A convivência com a diferença e com o diferente foi um tema que os jovens pontuaram com frequência em suas falas. Para Weller (2006, p. 246), "é principalmente no grupo que o jovem trabalhará, entre outras coisas, as experiências vividas no meio social, as experiências de desintegração, e exclusão social, assim como as inseguranças geradas a partir destas situações".

O grupo de discussão foi escolhido por propiciar uma dinâmica conversacional, assim como as dissonâncias e contradições construídas discursivamente, como afirma Souza (2016, p. 197):

Por meio da integração desenvolvida por esse método, os sujeitos partícipes da pesquisa poderão refletir, revelar e registrar uma realidade que é vivenciada coletivamente por eles(as). Esse método possibilita ao(à) pesquisador(a) estabelecer relações e semelhanças entre as práticas e experiências de mundo que são expostas pelos(as) integrantes do grupo durante seu desenvolvimento, tornando-se um notável método quando se busca estudar um contexto social específico e quando se deseja considerar as experiências coletivas vividas por esses sujeitos.

O desenvolvimento deste estudo, baseado nas premissas de uma pesquisa qualitativa, possibilitou que atores jovens revelassem sentidos e significados construídos a partir dos processos educativos e formativos que se dão tanto no contexto escolar quanto no social, no familiar e no religioso sobre diversidade de gênero, buscando analisar os rituais e as provas de masculinidades vividas por eles nos diferentes contextos de socialização: família, religião e escola. 
A partir das narrativas dos(as) jovens, buscou-se evidenciar as contradições, os desafios e a novidade trazida em cada forma de viver-experimentar e construir as identidades de gênero e identidades sexuais. Para a pesquisadora, foi um desafio criar um ambiente que favorecesse à conversa e, ainda assim, constituísse um espaço de confiança entre pesquisadora e participante, rompendo com a hierarquia na relação adulto-jovem, assim como na assimetria de gênero.

Em seguida serão discutidos alguns dados produzidos nos grupos de discussão, dispositivo escolhido preferencialmente pela potência interativa e discursiva, que gerou novos posicionamentos e ampliação da concepção de si e do outro.

\section{Discutindo os resultados: significados sobre masculinidades juvenis}

Os(as) jovens demonstraram respeito mútuo e acolhimento nos relatos trazidos nos grupos de discussão, espaço em que foi possível criarem um vínculo de confiança para a desconstrução e construção de saberes em torno das concepções e vivências sobre masculinidade, sem omitirem as tensões e os desacordos nas formas de abordarem os temas. Preconceito, violência, discriminação, padrões sociais foram termos bastante mencionados nos encontros.

Jovem do sexo masculino, 16 anos: Apesar de eu não ser gay, eu sou um homem afeminado e na questão de ser afeminado... as pessoas... Assim, desde pequeno eu sofri bullying por causa disso. Existiu uma época que eu entrei em uma depressão. Uma depressão na qual eu me mutilava... eu já passei por isso. Mas sim... isso aconteceu comigo na escola, dentro de casa, na igreja onde eu frequento... era uma situação ruim. Eu me sentia constrangido. E eu até hoje não consigo passar em um grupo de pessoas. Por exemplo, eu andar na rua e ta passando um grupo de meninos na minha direção eu prefiro atravessar a rua porque eu não me sinto muito bem. Isso pra mim, me trouxe isso, a questão de. [...] Era uma situação constrangedora. Eu estava no meio de duas pessoas... no meio de uma sala e só por eu ter feito um gesto pessoas viam até a mim e me criticavam... e era tipo... aquela sala toda e eu ali sozinho recebendo toda aquela crítica. Então isso me constrangia... isso me dava pânico. era uma situação constrangedora demais. (SANTOS, 2019, p. 110-111).

As diferentes opressões foram destacadas em algumas falas, remetendo ao fato de que ser jovem homem e negro é perigoso e ser jovem homem, negro e homossexual é mais difícil ainda. Muitos apontaram para uma tensão vivida por eles/elas entre sua própria existência e as exigências sociais, familiares e religiosas sobre como e o que é ser homem e ser mulher. As questões relacionadas à identidade sexual foram trazidas como questões que geram dúvidas, medo e insegurança. Os jovens homens afeminados, relataram a oportunidade de falar desse lugar "fora da regra" e não normativo, tendo sido acolhidos e respeitados.

Os jovens e as jovens demonstram em seus relatos que querem ser sujeitos de sua própria vida e apontaram para o conflito entre a correspondência com os papéis de gênero como atribuição naturalizada (a partir do corpo biológico como marca do feminino e do masculino) e as identidades sexuais multifacetadas que experimentam na juventude (como condição da diferença que institui a nossa humanidade).

Os rituais de passagem, que o adolescente enfrenta para tornar-se um homem adulto, embora em declínio ou difusos na sociedade contemporânea, como nos faz refletir Bourdieu (2002), ainda possuem força, criam constrangimentos e ditam os comportamentos do masculino entrelaçados às ideias da virilidade, da força e da coragem, sem questionar os efeitos desses processos nas vidas dos jovens homens.

O relato do jovem de 17 anos do sexo masculino que se identifica como homem afeminado ilustra os rituais de passagem experienciados na adolescência, que são relacionados à constituição 
da masculinidade: "na adolescência eu comecei a construir isso [provar que é homem] ficando com garotas. A primeira menina que eu fiquei eu tinha 12 anos". O jovem ressaltou o estabelecimento da relação amorosa com uma mulher como marco importante para ser reconhecido como homem, o que leva a se pensar sobre o porquê da necessidade de a família ter a confirmação em relação à identidade de gênero e à identidade sexual dos filhos, a fim de que se problematize a naturalização dos papéis do homem dentro da família e da sociedade.

Sobre o modelo hegemônico de masculinidade associado aos ideais de virilidade e de força, a fala do jovem de 21 anos do sexo masculino e que se identifica como homem macho, sinaliza para construções sociais a respeito da adoção desse modelo de masculinidade. Quando foi perguntado ao jovem se ele considera que há diferenças entre ser homem e ser macho, ele afirmou que: "ser homem é ter uma responsabilidade com a família e com os demais. E ser macho é só ser homem... ser do sexo masculino". E para exemplificar o que seria ser macho, ele disse: "é andar como homem, falar como homem". Ao ser questionado sobre o que seria falar como homem, ele afirmou: "é falar grosso, falar forte, falar com autoridade".

Já o jovem de 15 anos, evangélico e que se identifica como homem homossexual, ressalta a cobrança para ser macho como uma forma de regular o comportamento do homem: "ser macho é mais o que o povo pressiona. Ter voz de macho. Ter uma postura [...] jeito de ser mexer [...] homem macho não se mexe. Quando é muito expressivo não tem característica de macho". A fala desse jovem evidencia a exigência social para que homens adotem uma "postura de homem macho", reforçando o ideal de uma masculinidade hegemônica.

Enquanto as masculinidades hegemônicas são legitimadas socialmente por se relacionarem às características de virilidade, de valentia, de força, dentre outros atributos; as masculinidades subalternas não são reconhecidas como condutas normais por fugirem ao padrão de ser homem convencionado pela sociedade (MACHADO; SEFFNER, 2013).

Como já sinalizado anteriormente, os(as) jovens, mesmo imersos em uma constituição familiar, cuja organização hierárquica quase sempre reproduz o modelo patriarcal, constroem caminhos alternativos, contradizendo o padrão normativo ainda vigente. De acordo com Setton (2005, p. 345), "a identidade social e individual [...] não se realizaria mais a partir de uma correspondência contínua entre indivíduo e sociedade, entre papéis propostos pelas instituições e sua integral identificação pelos indivíduos", como pode-se observar no relato a seguir:

Jovem do sexo feminino, 17 anos: Antigamente eu sofria muito preconceito. Quando eu tinha terminado com um menino há muito tempo atrás, aí me perguntaram : 'tu terminou com ele por quê? É porque tu é sapatona?’. A minha única reação foi sair daquele meio ali e ir pra minha casa e me isolar. Eu passei o dia todo sem sair de casa, sem comer nada. Não sentia fome, não sentia nada. Só desprezo, porque eu acabei me sentindo um lixo, porque um preconceito, velho. Eu acho que tem horas que eu sinto nojo do meu pai. Como ele fala, como ele me trata. Ele não me aceita. Isso me dói muito. (SANTOS, 2019, p. 78).

A jovem de 17 anos, bissexual e que se identifica como mulher masculinizada, traz, em seu relato, aspectos pertinentes para problematizar práticas de violência simbólica que acontecem dentro da própria família, tendendo a regular e controlar o que se acredita estar errado em detrimento da reflexão das diferentes experiências juvenis. Sua fala também sinaliza para a vivência da masculinidade em corpos femininos. A jovem se identifica como mulher masculinizada e bissexual e pontua que essas identidades são motivadoras de experiências discriminatórias dentro de casa e no bairro em que mora.

Pontos de vista diferentes puderam ser colocados em discussão tendo como base de fundamento a religião cristã, como podemos observar na continuação da conversa abaixo: 
Jovem do sexo feminino 2: É preconceito.

Jovem do sexo feminino 1: Porque assim, eu fui nascida e criada no evangelho.

Jovem do sexo feminino 2: Aí é preconceito... Isso é preconceito.

Jovem do sexo feminino 1: Mas é que eu fui criada numa doutrina de um jeito, aí tipo assim, pra mim, eu não tenho nada contra, tenho amigas sapatonas, adoro amizades com sapatonas, melhor amizade que tem, mas... na minha opinião eu não acho certo. Pra mim, Deus fez o homem e a mulher, pra mim, mas adoro um bocado, sou apaixonada.

Jovem do sexo feminino 2: Muita gente fala... Ah é pecado. Não é pecado. Como Deus disse: amar ao próximo como assim mesmo. Não é porque eu gosto dela que eu vou chegar e vou pegar. Não é assim não gente. Eu sou uma pessoa, muita gente sabe... poucas pessoas sabem que eu sou bissexual. (SANTOS, 2019, p. 90)

É importante considerar que diante das múltiplas experiências do sujeito, é passível de questionamento a adoção unânime de uma masculinidade hegemônica, porém é relevante, principalmente atualmente, problematizar os efeitos e consequências dessa exigência social, colocada como constituição natural da identidade de gênero.

Deparou-se com uma realidade desafiadora e complexa, que requereu compromisso e respeito pela realidade que se quis conhecer, valorizando e reconhecendo as vozes dos sujeitos envolvidos no estudo. Dessa forma, é pertinente refletir-se sobre como o gênero tem sido pautado no cotidiano escolar, ou seja, pensar sobre como os processos educativos têm colaborado para a naturalização das relações de gênero ou se esses estão legitimando e reforçando desigualdades de gênero por meio das práticas educativas.

Importante também foi problematizar a função social e educativa da escola, já que "os processos educativos são formadores de identidades, e não simplesmente mediadores". (SEFFNER, 2016, p. 17). Machado e Seffner (2013) pontuam a importância de pensar a masculinidade como construção cultural, mas também ressaltam que é imprescindível "conhecer e denunciar as estratégias e os mecanismos, conscientes ou inconscientes, de imposição das desigualdades de gênero" (MACHADO E SEFFNER, 2013, p. 374).

Observou-se que as ferramentas dialógicas e participativas foram priorizadas na pesquisa com jovens: a imersão das pesquisadoras em campo, as relações intersubjetivas construídas com os jovens, a dimensão ética do cuidado e reconhecimento da alteridade. Essas estratégias possibilitaram que os(as) jovens ressignificassem algumas experiências vividas, ao mesmo tempo em que puderam expressar suas identidades e diferenças. Pôde-se atestar que o protagonismo dos jovens durante a pesquisa, em conjunto com a escuta sensível das pesquisadoras, produziu um efeito importante de empoderamento e reconhecimento, trazendo à tona a demanda dos jovens de que a escola promovesse espaços de debate e de participação.

\section{Considerações finais}

A perspectiva que se assumiu aqui é de que as experiências coletivas reverberam internamente, reconfigurando as subjetividades e as posições que o $\mathrm{eu}$ assume socialmente. Considerou-se que o diálogo construído com os jovens acerca da temática de gênero provocou rupturas e descontinuidades na percepção de si, possibilitando, assim, novos posicionamentos e mudanças de significados e sentidos construídos no decorrer da pesquisa.

Os efeitos produzidos pela pesquisa com jovens evidenciam a importância do lugar de fala e de escuta que se estabeleceram entre pesquisadoras e jovens. Questiona-se de que formas as instituições escolares estão promovendo espaços de encontro, diálogo e criticidade no desenvolvimento 
das consciências desses jovens, na construção do respeito à diferença e do direito à diferença. A importância das narrativas produzidas, ao longo das pesquisas, é não reificar lugares sociais estigmatizados e lançar luz sobre a dinâmica de forças do jogo social e da política da diferença, como elementos importantes na pesquisa com jovens.

Os relatos juvenis sinalizaram para a importância de trazer para o debate as construções identitárias em torno do que se convencionou ser o homem macho, como também sobre o modelo de mulher associado a um lugar de inferioridade. Problematizou-se ainda os efeitos e as consequências para homens e para mulheres da ação destes modelos, bem como promoveu-se reflexões sobre a ideia construída socialmente de que esses modelos não precisam ser discutidos, já que são impostos como realidade natural do homem e da mulher, com base na lógica binária dos sexos.

Os(as) estudantes evidenciaram em suas falas, a família e a religião como espaços de afeto e de acolhimento, mas também de regulação e disciplinamento, assim como incentivadores e promotores de práticas discriminatórias. Os(as) jovens sofrem experiências de preconceito, violência verbal e simbólica e até física dentro da própria família, quando escapam à adoção de um modo único de ser homem e de ser mulher.

Por fim, o desenvolvimento desse estudo possibilitou que jovens revelassem sentidos e significados construídos a partir dos processos de socialização e sociabilidade sobre diversidade de gênero, destacando-se as diferentes construções de masculinidades entre os gêneros femininos e masculinos em articulação com as experiências juvenis na contemporaneidade, na relação com o corpo, com a estética, com a sexualidade e com os afetos dentro e fora da escola. As narrativas revelaram discursividades contra-hegemônicas ao discurso social conservador, que opera sobre as subjetividades juvenis, sobretudo quando se observam as provas (desafios) que vivenciam para expressarem suas diferenças. Apesar da escuta propiciada pela pesquisa, pode-se afirmar que as instituições socializadoras tradicionais ainda estão longe de possibilitarem a livre expressão e "performatividade" de gênero entre jovens.

\section{Referências}

BOURDIEU, Pierre. A Dominação Masculina. Tradução de Maria Helena Kuhner. 2. ed. Rio de Janeiro: Editora Bertrand Brasil, 2002.

CARRANO, Paulo. Jovens, escolas e cidades: entre diversidades, desigualdades e desafios à convivência. In: COLÓQUIO LUSO-BRASILEIRO DE SOCIOLOGIA DA EDUCAÇÃO, 2., 2009, Porto Alegre. Anais [...]. Porto Alegre, 2009. Disponível em: https://www.academia.edu/1204543. Acesso em: 18 mar. 2017.

CONELL, Robert W.; MESSERSCHMIDT, James W. Masculinidade Hegemônica: repensando o conceito. Estudos Feministas, Florianópolis, v. 21, n. 1, p. 241-282 jan./abr. 2013.

FERREIRA, Vitor Sérgio. Caminhos e desafios metodológicos na pesquisa com jovens. In: FERREIRA, Vitor Sérgio (org.). Pesquisar Jovens: caminhos e desafios metodológicos. 1. ed. Lisboa: ICS Instituto de Ciências Sociais, 2017. p. 17-31.

FERREIRA, Vitor Sérgio; RAIMUNDO, Alexandra. Conversas entre jovens: o uso youthfriendly de grupos focais. In: FERREIRA Vitor Sérgio (org.). Pesquisar Jovens: caminhos e desafios metodológicos. 1. ed. Lisboa: ICS Imprensa de Ciências Sociais, 2017. p. 57-90.

GERMANO, Idilva; BESSA, Letícia Leite. Pesquisas narrativo-dialógicas no contexto de conflito com a lei: considerações sobre uma entrevista com jovem autora de infração. Subjetividades, Fortaleza, v. 10, n. 3, p. 995-1033, set. 2010.

JOCA, Alexandre Martins. Levados por Anjos: modos de vida, educação e sexualidades juvenis. 2. ed. Curitiba: Editora CRV, 2016.

LOURO, Guacira Lopes. Pedagogias da Sexualidade. In: LOURO, Guacira Lopes (org.). O corpo educado: pedagogias da sexualidade. 3. ed. Belo Horizonte: Autêntica Editora, 2016. 
MACHADO, Vanderlei; SEFFNER, Fernando. Florianópolis 1889/1930: estratégias de produção simultânea de masculinidades hegemônicas e subordinadas. História, São Paulo, v. 32, n. 1, p. 354-376, 2013. Disponível em: https://www. scielo.br/j/his/a/7rK8r3kTBs8cxFgjfrBddQk/abstract/?lang=pt. Acesso em: 22 jan. 2021.

MIRANDA, Luciana Lobo et al. Pesquisando com jovens na escola: desafios da pesquisa-intervenção em dois contextos escolares. Psicologia Escolar e Educacional, v. 20, n. 2, p. 245-254, 2016.

SANTOS, Neide Pinto dos. Juventudes e Masculinidades: conversando sobre gênero com estudantes em uma escola pública no município de Feira de Santana-BA. 2019. Dissertação (Mestrado em Educação) - Programa de Pós-Graduação em Educação, Universidade Estadual de Feira de Santana, Feira de Santana, 2019. Disponível em: http://tede2. uefs.br:8080/handle/tede/884. Acesso em: 13 set. 2020.

SEFFNER, Fernando. Derivas da Masculinidade: Representação, Identidade e Diferença no âmbito da masculinidade Bissexual. 1. ed. Jundiaí: Paco Editorial, 2016.

SETTON, Maria da Graça Jacintho. A particularidade do processo de socialização contemporâneo. Tempo Social, São Paulo, v. 17, n. 2, p. 335-350, 2005. Disponível em: https://doi.org/10.1590/S0103-20702005000200015. Acesso em: 22 jan. 2017.

SOUZA, Kamila Costa de. Entrelaçar falas e desvelar o cotidiano camponês: o grupo de discussão na pesquisa com jovens do campo. In: DAMASCENO, Maria Nobre; SALES, Celecina de Maria Veras; ALMEIDA, Nadja Rinelle Oliveira de (org). Pesquisa Qualitativa: formação e experiências. Curitiba: CRV, 2016. p. 195-213.

WELLER, Wivian. Grupos de discussão na pesquisa com adolescentes e jovens: aportes teóricos metodológicos e uma análise de uma experiência com o método. Educação e Pesquisa, São Paulo, v. 32, n. 2, p. 241-260, maio/ago. 2006.

Data de submissão: $31 / 01 / 2021$

Data de aceite: $12 / 02 / 2021$ 